Journal of Bangladesh Academy of Sciences, Vol. 39, No. 1, 91-101, 2015

\title{
DEVELOPMENTAL STAGES OF A COMMON EMIGRANT BUTTERFLY CATOPSILIA CROCALE FABRICIUS AND ITS ASSOCIATION WITH THE HOST PLANT CASSIA ALATA
}

\author{
H. ARJU, M.K. MIAH, N. PARVEN AND M.A. BASHAR*
}

Environmental Biology and Biodiversity Laboratory, Department of Zoology, University of Dhaka, Dhaka-1000, Bangladesh

\begin{abstract}
Developmental stages of pierid butterfly Catopsilia crocale Fabricius (Lepidoptera: Pieridae) and its association with Cassia alata: Family-Leguminosae (host plant) was studied in the laboratory under $24 \pm 5^{\circ} \mathrm{C}$ temperature with RH $66 \pm 2 \%$. The host plant association and duration of developmental stages was given importance. Duration of life cycle (egg to adult) was $22.0 \pm 0.8$ days. The incubation period, larval and pupal period were $6.65 \pm 0.4,10.1 \pm 0.8$ and $6.5 \pm 0.44$ days, respectively. Eggs, five larval instars and pupal stages were distinct. Correlation was found among the development of larval instars, amount of food consumption and excretion of faeces. The association of $C$. crocale with host plant was characterized and evidenced by the use of $C$. alata leaves, buds, stems and shoots for egg laying and for complete development of the larval (9 - 11 days) and pupal (6 - 7 days) stages. The incubation period, different larval instars and pupal stage were found to be deeply associated with the phenological phases of the host plant.
\end{abstract}

Key words: Developmental stages, Larval instar, Association, Plant phenology, Synchronization

\section{INTRODUCTION}

Butterflies are particularly sensitive to environmental variations (Robbins and Opler 1997). These insects are very much related with their host-plants (Scoble 1992). Almost all butterflies are herbivores at larval stages, majority of them are host specific and have close relationship with their host plants (Price et al. 1991). Various behavioural aspects viz. foraging, resting, flying, mating and egg laying of Pierid butterflies are associated with the host plants (Barua and Slowick 2007). Positive relations have been found between butterflies and its host plant diversity (Leps and Spitzer 1990). The diversity of butterflies is now decreasing day by day as a result of climate changes, loss of forest ecosystem, etc (Molina and Palma 1996). The plant and butterflies relationship enables to establish Butterfly park, determine the forest ecosystem and help to assess the natural environment of forest (Bashar et al. 2005). Pieridae is the third largest butterfly family of the world with about 2000 described species (Fres 1989). Members of this family utilize various host plant species of Leguminosae for maintaining their developmental stages

\footnotetext{
* Corresponding author.
} 
(Boggs 1987). These butterflies are characterized mainly by white or yellow colouration, often with black spots. Each type of the vegetation can make unique contribution to measure butterfly diversity and butterflies for the plant diversity (Suzuki et al. 1997, Faegri and Vander 1996). Rearing of these butterfly species and related host plants in the wild condition will help restocking depleting population in forest ecosystem (Dosa 1999, Porter et al. 1992). To maintain the forest ecosystem, it needs to rare butterflies with specific host plants (Bashar et al. 2006). The genus Catopsilia is a member of the family Pieridae and subfamily Coliadinae. It is a common butterfly found all over in Bangladesh.

There are four species of the genus Catopsilia, namely $C$. pomona, $C$. pyranthe, $C$. florella and C. crocale in Bangladesh (Beeson 1941).The present study emphasized to identify the life stages of Catopsilia crocale and its association with Cassia alata. This theme was undertaken with a view to analyzing the host plant association at different developmental stages that could be utilized as a tool for butterfly colonization in the forest ecosystem.

\section{MATERIALS AND METHODS}

The study was conducted in the Environmental Biology and Biodiversity Laboratory (EBBL), Department of Zoology, University of Dhaka from July to October, 2009. The stems, young leaves, buds and shoots of $C$. alata and the eggs, larvae, pupae of $C$. crocale were collected from the Germplasm Centre (GPC) of Zoological Garden, University of Dhaka. The samples were collected once in a week during the study period.

Females were observed to lay eggs on the host plant at day light. The egg laying behaviour was observed by following the methods of Jermy and Szentesi (1978). The eggs were collected by cutting the host plant stems at $45^{\circ}$ angular areas. After cutting the stem, it was wrapped with wet cotton to make the stem alive. It was set up into a glass bottle containing water. The bottle with the stem was placed into a larvae-rearing cage. Two sets of rearing cages were used in this experiment. Each rearing cage had three edges. The length of first, second and third edge of rearing cage were 362.5, 350 and 350 $\mathrm{mm}$, wide were $300,287.5$ and $287.5 \mathrm{~mm}$ and the height were 150,125 and $62.5 \mathrm{~mm}$, respectively. First edge had no cavity, second edge was fully perforated and the third edge was the cover of the cage. These cages were used for the maintenance of proper humidity and limited air supply. Eggs were examined twice per day. The incubation period was observed by following the methods used by Bashar et al. (2008) and Arju et al. (2010).

Larvae were observed regularly for supplying food, collecting faeces and to identify the molting and mortality rate. Larval length was measured by using centimeter scale. Fresh leaves of host plant were supplied as food at 2 days interval for the first instars and one day 
interval for the second instars. Old foliage was removed regularly. The host plant was kept fresh by watering. The larval period of an instar was recorded between the time of first larval appearance and the first larva moult of the next instar with changes of morphological characteristic. Larvae were reared by following the method of Zalucki et al. (2002) and their feeding potential was measured according to the method used by Singh and Sing (1993). The amount of food consumption and faeces (gm) were recorded by using Precision Electronic Balances following the method of Barua and Slowik (2007).

Pupae with rearing cage were kept in the emergence cabinet (made by iron rod). It was rectangular in shape (length $525 \mathrm{~mm}$, width $450 \mathrm{~mm}$, and height $900 \mathrm{~mm}$ ) and covered by the muslin net to prevent the butterfly dispersion or flight when the adult emerged from the pupa. There were $8-10$ holes per $1 \mathrm{~cm}^{2}$ area in net for maintaining the proper light and aeration. Damp sponges were kept in the immergence cabinet for providing sufficient humidity.

The biology of the species was studied following Baker (1984), Alam et al. (2014), and Rao et al. (2006). The identification was made according to the methods of Borror et al. (1981).

\section{RESULTS AND DISCUSSION}

The different developmental stages, viz. egg, larva, pupa and adult of $C$. crocale were found to be characteristically associated with the phenological stages of its host plant C. alata.

Adult wing span of both sexes was 55 to $80 \mathrm{~mm}$ (forewing span $21-38 \mathrm{~mm}$ and hindwing span $20-28 \mathrm{~mm}$ ). Antennae were reddish and $9-13 \mathrm{~mm}$ in length. Dorsal side of forewing was pale yellow or white. Outer edge, tip and upper margin of the female wings were much more broadly black than those of the male. Basal area of both sexes was usually sulphur yellow. Ventral side has no marking in both sexes (Fig. 1 a, b).

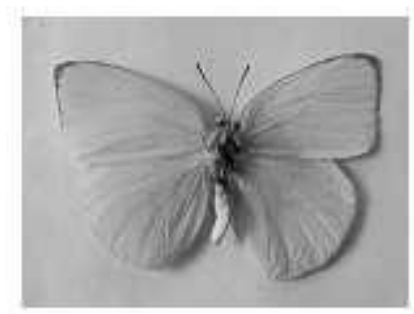

a) Dorsal view

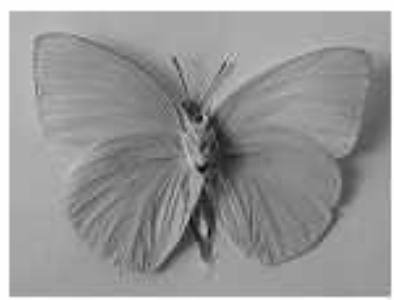

b) Ventral view

Fig. 1. External features of adult C. crocale.

Oviposion during searching the host plants, females vibrated their wings rapidly; searched the host plant-parts by touching and moving forward and started to lay eggs by 
bending its abdomen. Within one minutes they laid 15 to 25 eggs individually on young shoots and leaves of C. alata.

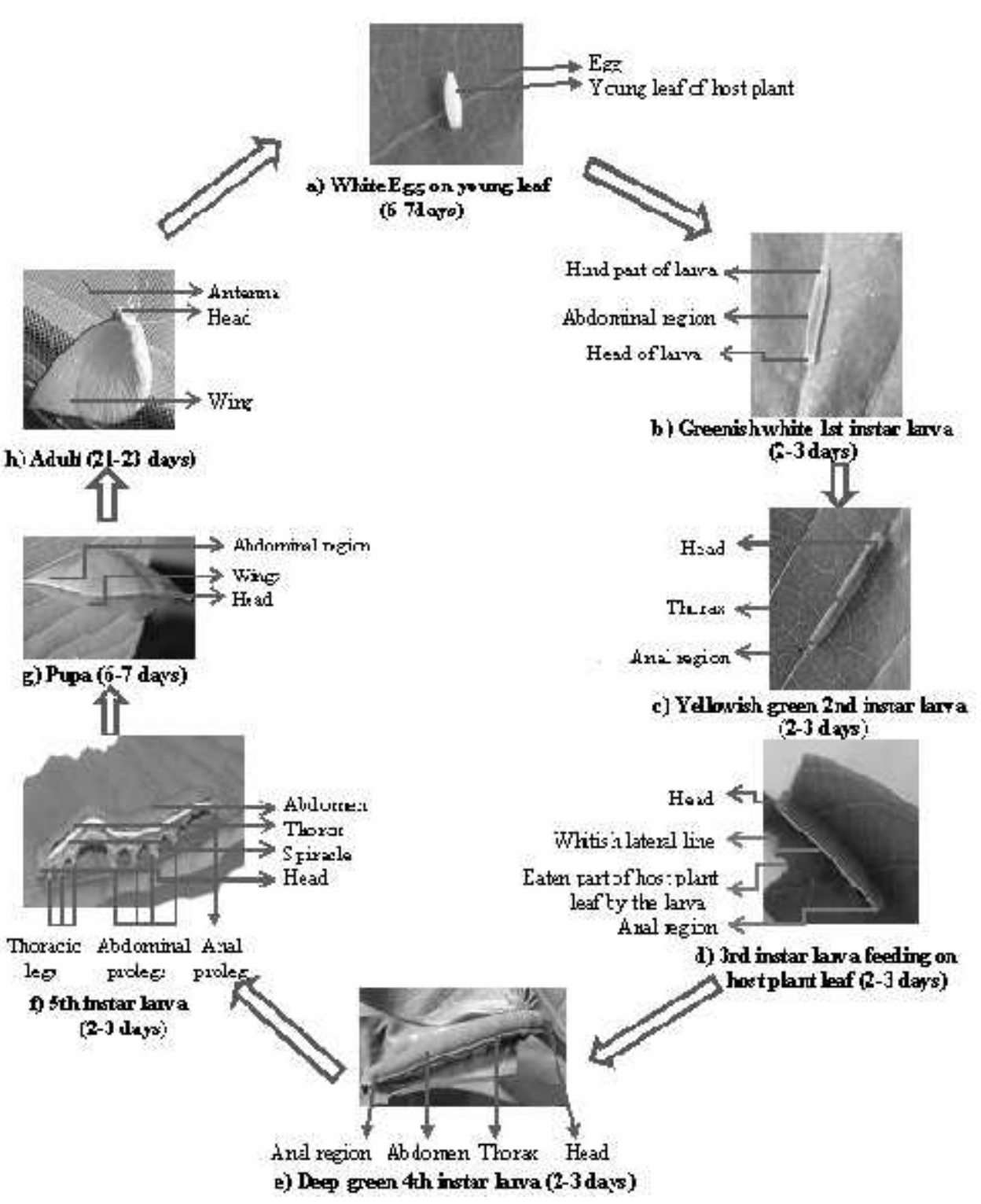

Fig. 2. Developmental stages of $C$. crocale.

Incubation period: Eggs are erect and spindle-shaped, measuring about $2 \mathrm{~mm}$ in length and $1 \mathrm{~mm}$ in diameter at the broadest part. The colour is white immediately after laying (Fig. 2a). It becomes creamy white within a day and turned darkish-white at the time of hatching. According to Garcia-Barros and Martin (1995) the shape and colour of the eggs of European Satyrine butterflies remained consistent during hatching. The 
average incubation period was recorded $6.65 \pm 0.4$ days. About $50 \%$ eggs hatched in 7 days, $27 \%$ in 6.5 days and $23 \%$ in 6 days, respectively (Fig. 3).

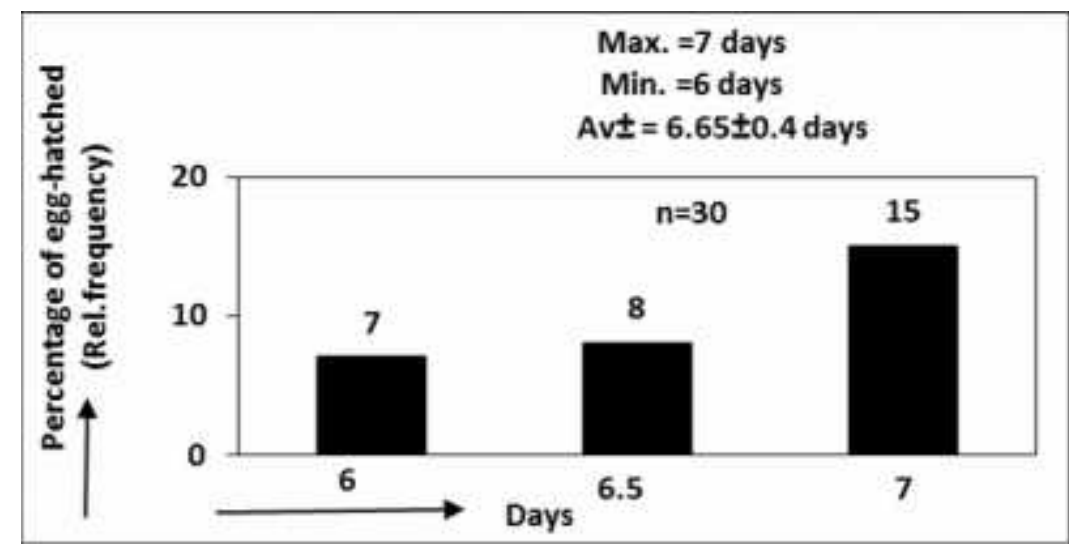

Fig. 3. Incubation period (in days) of C. crocale.

First instar larvae: Larvae were minute, cylindrical and greenish in colour. Average duration was $2.3 \pm 0.5$ days. The maximum length and width of the larvae were 8 and 2 $\mathrm{mm}$ respectively. Each lateral side had pale yellowish green line, dorso-lateral and lateral rows with small tubercles. Body segments were poorly visible by naked eye. Head was rounded and plain and diameter varied from 0.3 to $0.5 \mathrm{~mm}$. It consumed small amount of young host-leaf (Fig. 2b). The feeding and resting time was 1 - 2 and 60 - 70 minute respectively (Table 1). Atluri et al. (2004) reported that the duration of first instar Catopsilia pyranthe was 2 - 3 days and body length was $4.5-5.5(5.0 \pm 0.2) \mathrm{mm}$.

Second instar larvae: Larvae were yellowish green in colour, covered with rings of numerous small black tubercle, diameter varied from 0.6 to $1.3 \mathrm{~mm}$. Average duration was $2.3 \pm 0.5$ days. It consumed small amount of food and excreted less amount of black faeces (Fig. 2c). The total feeding and resting time recorded were 2-3 minutes and $60-70$ minutes, respectively. The maximum length and width of the larvae were 16 and $3.5 \mathrm{~mm}$, respectively (Table 1). Atluri et al. (2004) observed that the body of Catopsilia pyranthe at second instar was pale green, lateral sides yellow with pale yellow head. The length of instar period was 2 - 3 days and body length was $8.5-10.0(9.2 \pm 0.6) \mathrm{mm}$.

Third instar larvae: A faint yellow line appeared on the upper edge of the last of this developmental stage. Head diameter varied from 1.4 to $1.7 \mathrm{~mm}$ in this larval instar. Average duration was $2.3 \pm 0.5$ days. The average length and width were $20 \pm 0.8$ and $5.5 \pm$ $0.9 \mathrm{~mm}$, respectively. Legs and pro-legs were distinct in this stage (Fig. 2d). It fed very fast and grew rapidly. The feeding and resting time was 15 - 20 and 35 - 45 minute, respectively (Table 1). Arju et al. (2010) reported before that the body of Catopsilia pyranthe was green in colour with distinct black band. Legs and prolegs were very distinct. 
Fourth instar larvae: The white-yellow stacked lateral line was more prominent. Head was rounded, yellowish green in colour and diameter varied from 1.8 to $2.5 \mathrm{~mm}$. Average duration was $2.3 \pm 0.5$ days. At this developmental stage larvae consume host plant leaves voraciously (Fig. 2e). The larvae attained maximum $34 \mathrm{~mm}$ in length and 6.5 $\mathrm{mm}$ in width. The feeding and resting time was 25 - 30 and 55 - 65 minutes, respectively (Table 1).

Table 1. Analysis of association with host plant at larval and pupal stages with their morphic status.

\begin{tabular}{|c|c|c|c|c|c|c|}
\hline \multirow{2}{*}{$\begin{array}{l}\text { Stages (larval } \\
\text { and pupal) }\end{array}$} & \multicolumn{2}{|c|}{ Measurement of body size } & \multirow{2}{*}{$\begin{array}{l}\text { Duration of the } \\
\text { developmental } \\
\text { stage (days) }\end{array}$} & \multirow{2}{*}{$\begin{array}{l}\text { Feeding } \\
\text { Time } \\
(\min )\end{array}$} & \multirow{2}{*}{$\begin{array}{c}\text { Resting } \\
\text { Time(min) }\end{array}$} & \multirow{2}{*}{$\begin{array}{c}\text { Status of } \\
\text { Associated Host } \\
\text { plant parts. }\end{array}$} \\
\hline & Length (mm) & Width (mm) & & & & \\
\hline \multirow[t]{3}{*}{ First } & Min. 3 & Min.1.5 & Min. 2 & $1-2$ & $60-70$ & $\mathrm{YL}=+++$ \\
\hline & Max. 8 & Max.2.0 & Max. 3 & & & $\mathrm{TL}=+++$ \\
\hline & Av. $\pm=7 \pm 0.8$ & Av. $\pm=1.75 \pm 0.8$ & Av. $\pm=2.3 \pm 0.5$ & & & $\mathrm{ML}=+$ \\
\hline \multirow[t]{3}{*}{ Second } & Min. 9 & Min.2.5 & Min. 2 & $2-3$ & $60-70$ & $\mathrm{YL}=+++$ \\
\hline & Max. 16 & Max.3.5 & Max. 3 & & & $\mathrm{TL}=+++$ \\
\hline & Av. $\pm=15.3 \pm 0.5$ & Av. $\pm=3 \pm 0.7$ & Av. $\pm=2.3 \pm 0.5$ & & & $\mathrm{ML}=+$ \\
\hline \multirow[t]{3}{*}{ Third } & Min. 17 & Min.4.5 & Min. 2 & $15-20$ & $35-45$ & $\mathrm{YL}=++++$ \\
\hline & Max. 21 & Max.6 & Max. 3 & & & $\mathrm{TL}=++++$ \\
\hline & Av. $\pm=20 \pm 0.8$ & Av. $\pm=5.5 \pm 0.9$ & Av. $\pm=2.3 \pm 0.5$ & & & $\mathrm{ML}=++$ \\
\hline \multirow[t]{4}{*}{ Fourth } & Min. 22 & Min.6 & Min. 2 & $25-30$ & $55-65$ & $\mathrm{YL}=++++$ \\
\hline & Max. 34 & Max.6.5 & Max. 3 & & & $\mathrm{TL}=++$ \\
\hline & Av. $\pm=32 \pm 0.8$ & Av. $\pm=6.25 \pm 0.9$ & Av. $\pm=2.3 \pm 0.5$ & & & $\mathrm{ML}=+++$ \\
\hline & & & & & & $\begin{array}{l}\mathrm{IST}=+ \\
\mathrm{OL}=+\end{array}$ \\
\hline \multirow[t]{4}{*}{ Fifth } & Min. 35 & Min.7.5 & Min. 2 & $30-35$ & $50-60$ & $\mathrm{YL}=++++$ \\
\hline & Max. 45 & Max.10 & Max. 3 & & & $\mathrm{TL}=+++$ \\
\hline & Av. $\pm=44 \pm 0.8$ & AV. $\pm=8.7 \pm 0.8$ & Av. $\pm=2.2 \pm 0.4$ & & & $\mathrm{ML}=+++$ \\
\hline & & & & & & $\begin{array}{l}\mathrm{IST}=+ \\
\mathrm{OL}=+\end{array}$ \\
\hline \multirow[t]{3}{*}{ Pre-pupal } & Min. 30 & Min.6.5 & Min.1 & Non & Full resting & $\mathrm{MST}=+++$ \\
\hline & Max. 37 & Max.7 & Max.1.5 & feeding & in mode & $\mathrm{OL}=+++$ \\
\hline & Av. $\pm=33.5 \pm 0.8$ & Av. $\pm=6.75 \pm 0.9$ & Av. $\pm=1.25 \pm 0.6$ & & & $\mathrm{NGP}=+$ \\
\hline \multirow[t]{3}{*}{ Pupal } & Min.28 & Min. 12 & Min. 6 & Non & Full resting & $\mathrm{MST}=+++$ \\
\hline & Max.30 & Max. 14 & $\operatorname{Max}=7$ & feeding & in mode & $\mathrm{OL}=+++$ \\
\hline & Av. $\pm=29 \pm 0.8$ & Av. $\pm=13 \pm 0.8$ & Av. $\pm=6.5 \pm 0.5$ & & & $\mathrm{NGP}=+$ \\
\hline
\end{tabular}

Status of host plant parts: $\mathrm{YL}=$ Young leaf, $\mathrm{TL}=$ Tender leaf, $\mathrm{ML}=$ Mature leaf, $\mathrm{IST}=$ Immature stem, $\mathrm{OL}=$ Old leaf, MST $=$ mature stem, $\mathrm{NGP}=$ Neighbor plant,

Status of association: $++++=$ Deeply associated $(90 \%$ to above), $+++=$ Highly associated $(60-$ $90 \%),++=$ Moderately associated $(30-60 \%),+=$ Poorly associated $(10-30 \%)$.

Fifth instar larvae: Segments of thoracic region was very distinct. In each segment a pair of true legs was also distinct. The abdomen was ten segmented with anal prolegs in the last segment (Fig. 2f). Average duration was $2.2 \pm 0.4$ days. The maximum length and width of the larvae were 45 and $10 \mathrm{~mm}$ respectively. At this stage the larvae also 
consumed leaves as their food voraciously and excreted a huge amount of faeces. The feeding and resting time was $30-35$ and 50 - 60 minute respectively. The length of this instar period was 3 - 4 days and body length was 29 - $36(30 \pm 0.1) \mathrm{mm}$ (Table 1). Atluri et al. (2004) reported that the body colour of Catopsilia spp. was green, segmentation clearly visible, lateral side yellow with black band and anal region pale green.

Average larval duration was recorded $10.1 \pm 0.8$ days. $46 \%$ larvae were turn into pupae on 11 days, $26.9 \%$ were 10 days and 26.9\% were 9 days, respectively (Fig. 4). Arju et al. (2010) observed that about $23.21 \%$ larvae of Catopsilia pyranthe pierids came into pupal stage after 10 days of development and $60.71 \%$ on 11 days and maximum duration of development was 12 days.

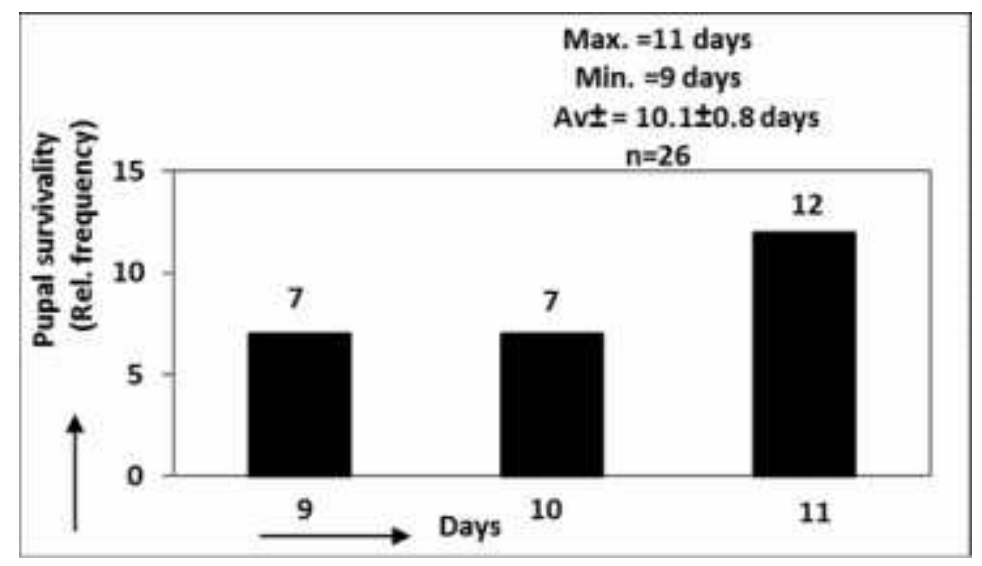

Fig. 4. Duration of larval period of C. crocale.

Positive correlation among the larval instar and the amount of food consumption was observed. The maximum food consumptions were recorded as $1.37 \mathrm{gm}$ and minimum $0.13 \mathrm{gm}$ in first instar (Fig. 5).

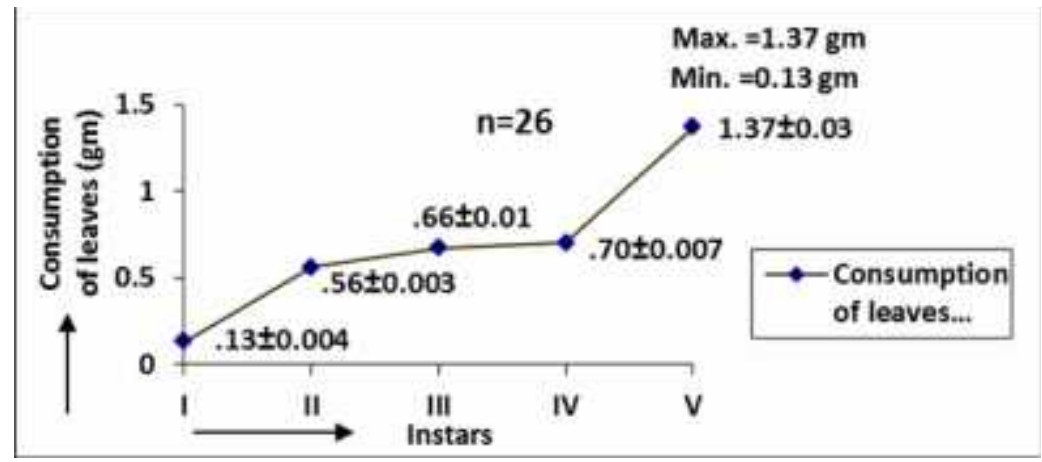

Fig. 5. Leaves consumed (in gram) by each larval instar.

With the developmental stages the amount of faeces found to be related. The highest amount of faeces was recorded $0.347 \mathrm{gm}$ and lowest $0.004 \mathrm{gm}$ at the first larval instar (Fig. 6). 
Pre-pupal stage: The final instar larval length and width measured 30 - 37 and $6.5-7 \mathrm{~mm}$, respectively. Body colour changed to a dull shade of pale green. The larvae gradually shrinked and ceased eating and wandered around for searching a pupation site. At the chosen site of host plant, the larvae settled itself for pupation by spinning a silk girdle.

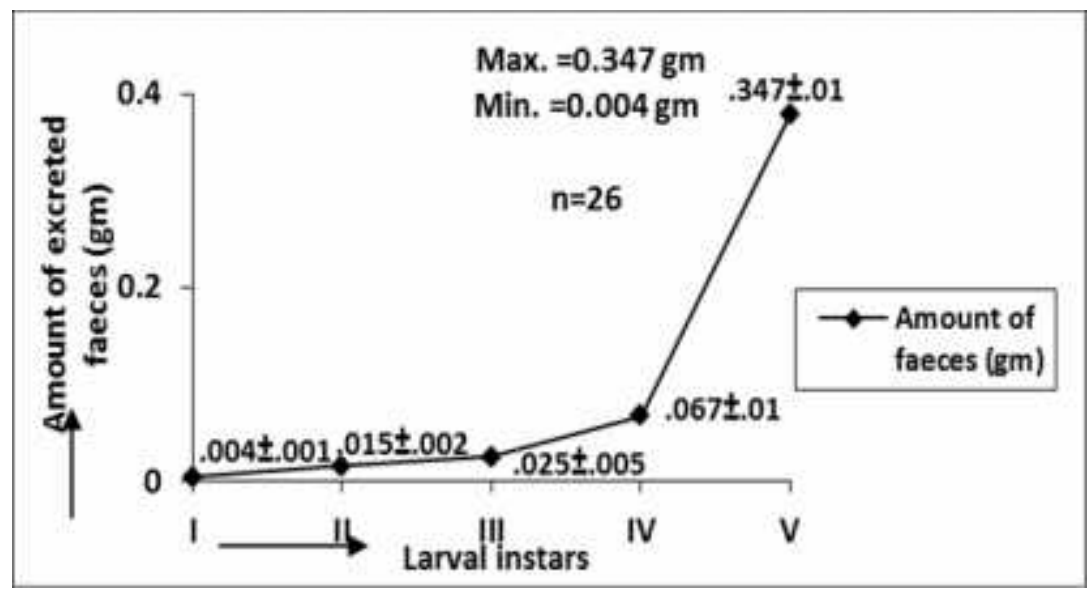

Fig. 6. Amount of excreted faeces (in gram) after each moulting.

Pupal stage: Pupation period started after one day of the pre-pupal stage. The length and width were 28 - 30 and 12 - $14 \mathrm{~mm}$, respectively. The pupa had a pointed head. Its yellowish green body had a yellow lateral line on each side. There was a dorsal protrusion with a yellow ridge line on the thorax. The keel formed by the tapering wing case was slightly pronounced (Fig. $2 \mathrm{~g}$ ).

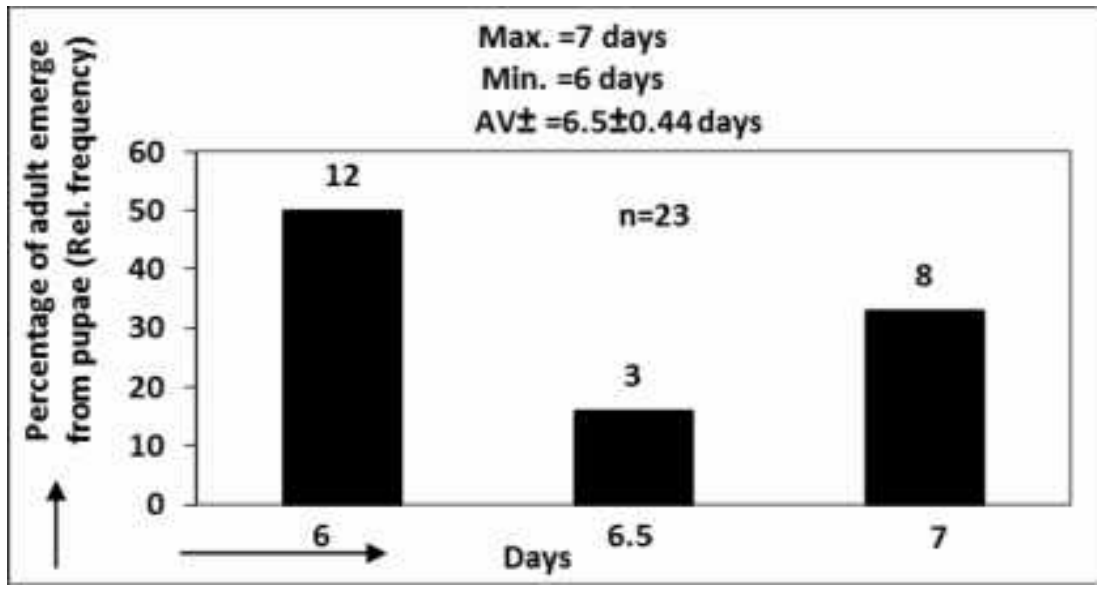

Fig. 7. Pupal period (in days) of C. crocale.

About 52\% pupae emerged as adults after 6 days, 35\% after 7 days and only $13 \%$ after 6.5 days. The average period of emergence was recorded $6.5 \pm 0.44$ days (Fig. 7). 
Pre-emergence stage: During the period of emergence the pupal skin turned translucent. The yellow colouration and black borders on the forewing upper side were then discernible. The adult butterfly emerged from the pupal case.

Emergence of butterfly: The adult emerged from pupal case. After the emergence, the crumpled wings of the adult expanded and smoothened out due to the pressure of the blood. This time they excreted yellow fluid from the body (Fig. 2h).

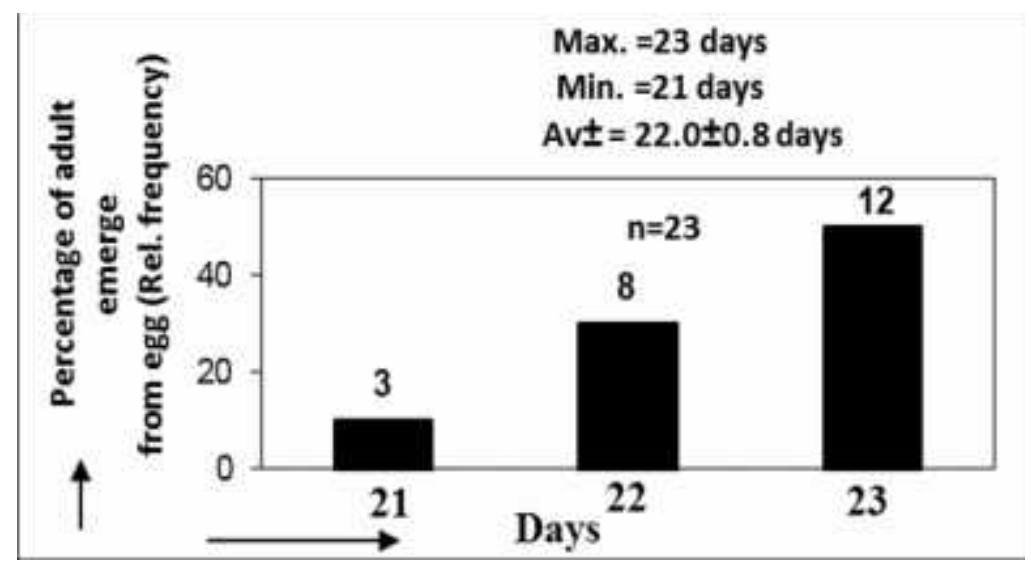

Fig. 8. Life duration of $C$. crocale (from egg to adult).

About 52\% eggs hatched after 23 days, 35\% after 22 days and 13\% after 21 days, respectively. The average duration from egg to adult was recorded as $22.0 \pm 0.8$ days (Fig. 8).

Phenological stages of Cassia alata associated with the life cycle of Catopsilia crocale: $C$. crocale was found to be deeply associated with the phenology of $C$. alata (host plant) specially the young buds, stems and leaves used for egg laying, food source and to complete the larval and pupal stages. There was a synchronization between the host plant's phenology and the developmental stages of the butterfly. Characteristically variations were found in the consumption of the host plant-parts (young buds and leaves) by the larvae. The consumption of the plant-parts was found to increase from the $1^{\text {st }}$ larval instar to successive developmental stages. Coincidences were observed between the plant reproductive stage (fruitification) and the developmental stages of the butterfly (Gladstone et al. 1998).

\section{REFERENCES}

Alam, M.M., M.A. Bashar and H.R. Khan. 2014. Biology of common rose butterfly Pachliopta aristolochiae Fabricius (Lepidoptera : Papilionidae) on the host plant, Aristolochia indica L. (Aristolochiaceae). Dhaka Univ. J. Biol. Sci. 23(2):109-117.

Arju, M.H., M.A. Bashar and G. Moula. 2010. Developmental stages of mottled emigrant butterfly (Catopsila pyranthe) in laboratory. Dhaka Univ. J. Biol. Sci. 19(2): 171-179. 
Atluri, J.B., S.P.V. Ramana and C.S. Reddi. 2004. Ecobiology of the tropical pierid butterfly Catopsilia pyranthe. Curr. Sci. 86(3): 457-461.

Baker, R.R. 1984. The biology of butterflies. Royal Entomological Society of London. Academic Press, London, pp. 279-296.

Barua, K.K. and J. Slowik. 2007. Study on the biology and consumption potential of Common Rose, Pachliopta aristolochiae (Lepidoptera: Papilionidae) on Aristolochia tagala. Polish J. Ent. 76: 341-352.

Bashar, M.A., M.A. Mamun and S.M. Rahman. 2005. Wing venation as a factor for the identification of Pierid butterflies in the forests of Bangladesh. Bangladesh J. Zool. 34(1): 4956.

Bashar, M.A., M.A. Mamun., A.F.M. Aslam and M.A.K. Chwdhury. 2006. Wing-venation as a factor for the identification of Nymphalid butterflies in the forests of Chittagong and Cox,s bazar Bangladesh. Bangladesh J. Zool. 34(2): 55-67.

Bashar, M.A., N. Parveen and M.A.K. Chowdhury. 2008. Case-making insect pest (Sinclita occidentalis: Pyralidae) and its characteristics association with duckweeds in minipond ecosystem. Dhaka.Univ. J. Biol. Sci. 17(2): 109-118.

Beeson, L.F.C. 1941. The ecology and control of the forest insects of India and the neighboring countries. Govt of India. pp. 1041.

Boggs, C.L. 1987. Ecology of nectar and pollen feeding in Lepidoptera. Nutritional Ecology of Insects, Mites, Spiders and Related Invertebrates. Wiley Press, New York. pp. 369 - 391.

Borror, D.J., D.M. Delong and C.A. Triphlehorn. 1981. An Introduction to The Study of Insects. CBS College Publishing. New York. 5: 476-549.

Dosa, G. 1999. Flower visitation pattern of butterflies and burnet moths in the Aggtelek-karst. Nota Lepid. 22: 58-66.

Faegri, K and P.L. Vander. 1996. The principles of pollination ecology. Pergamon Press, London, pp. 426.

Fres, P.S. 1989.The Illustrated Encyclopedia of the Butterfly World. Salamander Books Ltd. pp. 275.

Garcia-barros, E. and J. Martin. 1995. The eggs of European Satyrine butterflies (Nymphalidae): External morphology and its USE in systematics. Zool. Jour. Linnean Soc. 115(1):73-115.

Gladstone, J.S., C.A. ALKINS. and J. HAMBLIN. 1998. Lupinsas Crop Plants: Biology, Production and Utilization. PAB International, Wallingford Uk. pp. 1-353.

Jermy, T. and A. Szentesi. 1978. The role of inhibitory stimuli in the choice of oviposition site by phytophagous insects. Appl. Ent. Exp. 24: 458-468.

Leps, J. and K. Spitzer. 1990. Ecological determinants of butterfly communities (Lepidoptera, Papilionidae) in the Tam Dao Mountains, Vietnam. Acta Entomologica Bohemoslovaca. 87: 182-194.

Molina, J.M. and J.M. Palma. 1996. Butterfly diversity and rarity within selected habitats of western Andalusia, Spain (Lepidoptera: Papilionoidea and Hesperiodea). Nota Lepidopterologica 78: 267-280.

Porter, K., C. Steel and J.A. Thomas. 1992. Butterflies and Communities. The ecology of Butterfly in Britain. Oxford University Press, New York. pp. 139-177.

Price, P.W., G.W. Fernands., T.M. Lewinsohn and W.W. Benson. 1991. Plant-Animal Interactions. John Willey Inc. pp. 39.

Rao, A.R.K., T.M. Krishna., S.V.R.K. Rao., B.C. Reddy., K.H. Babu and K. Gopal. 2006. Studies on morphometrics and biology of citrus butterfly Papilio demoleus L. (Lepidoptera: Papilionidae) on acid lime, Citrus aurantifolia Swingle. Entomol. 515: 630-640. 
Robbins, R.K. and P.A. Opler. 1997. Butterfly diversity and a preliminary comparison with bird and mammal diversity. Joseph Henry Press, Washington D. C. pp. 69-82.

Scoble, M.J. 1992. The Lepidoptera: Form, Function and Diversity. Oxford University Press, New York. pp. 253.

Singh, I. and G. Singh. 1993. Assessment of foliage loss caused by different larval instars of Bihar hairy caterpillar, Spilosoma obliqua (Walker) on sunflower. J. Insect. Sci. 6(2): 185-186.

Suzuki, N., K. Yamashita., A. Nizuma and K. Kiritani. 1997. Studies on ecology and behavior of Japanese black swallowtail butterflies. Nectar feeding of Papilio helenus Butler and Protenor demetrius Cramer as main pollinators of glory bower. Ecol. Res. 2: 41-52.

Zalucki, M.P., A.R. Clarke and S.B. Malcolm. 2002. Ecology and behaviour of first instar larvae of Lepidoptera. Annual Review of Entomology 47: 361-393. 